four hours and a half). Spasms became less frequent, then less violent, and gradually ceased, some paralysis supervening. In the next few days there were occasional spasms, and a slight relapse. Disease disappeared on the eighth day.

Case 40.-Polli. ${ }^{15}$ Child aged twelve; attack eighty days after bite of rabid dog. Morphia injections and chloroform inhalations used ineffectually. Under curare (three grains in seven doses in five hours and a half) paroxysms rapidly yielded and were replaced by paralytic symptoms; in two days a slight relapse occurred, cured by another injection of half a grain.

Case 41.-Watson. ${ }^{16}$ Male, aged forty-eigbt, bitten on right forefinger, Dec. $20 \mathrm{th}$, by a rabid dog which bit four other persons, one of whom died of hydrophobia on Feb. 1st. Attack began on Feb. 6th after depression of from seven to ten days. Rigor, vomiting, tightness of præecordia, slow breathing, and attacks of respiratory spasms with much anxiety; any current of air caused shuddering and dread. The only aversion to fluids was shown by refusing cold water; he could drink warm fluids and had a considerable quantity of stimulants. Was treated by strychnia, one-twelfth of a grain every three hours until the fifth day, but grew worse, and was becoming exhausted by the respiratory spasms; then curare was given instead in doses of one-sixteenth of a grain, after which he soon became quiet and rational, lost his spasms, and recovered.

This is not a clear case, though infection was certain ; the phenomena were not typical, perhaps modified by strycbnia. However, Watson and Austin Flint, who both saw the case, agreed that it might be genuine.

[ERRATUM. - The reference of Case 9 (published last week) should be to Chambers' Journal, Feb. 12th, 1881, not 1884.]

$$
\text { (To be concluded.) }
$$

\section{TWO CASES OF \\ FATAL POISONING BY CARBOLIC ACID.}

BY J. H. DAVIES, M.D.,

MEDICAL OFFICER OF HEALTH FOR MARGAM, ETC.

ON New Year's eve two fatal cases of poisoning by carbolic acid occurred at Margam, Glamorgan, and came under my observation. One of the victims was a farm bailiff $(\mathrm{H}$ aged thirty years; the other a farm lad (T. D—) aged sixteen. The mishap occurred as follows:-A boy was sent to fetch a jar of beer from the cellar about 7.15 P.M., and in mistake brought up a jar containing a sheep-dip. The bailiff poured some of this into a jug, handed it to the farm lad, who drank a couple of mouthfuls, and exclaimed that he had had coal-tar; then the bailiff himself drank about half a tumblerful of the liquid, and, seeing that there was a mistake, he immediately called on the others not to take any of it. The lad had to be assisted to his home, which was distant a quarter of a mile. I saw the bailiff shortly before 11 o'clock. Owing to the farm being four miles from my house there was an interval of forty minutes between the reception of the message and my arrival. The patient was in bed, moaning, with his legs drawn up; foam and stains of a yellowish colour about the mouth; his pulse could hardly be felt; skin cold and clammy, and the face pallid, and covered with cold sweat; the pupils were contracted, and conjunctivæ congested. There had been free vomiting, and the vomited matter smelt strongly of carbolic acid. The man was in a semi-comatose and hopeless condition, and conld only with great difficulty be got to swallow some olive oil. He had frequent convulsive movements, principally contined to the facial muscles and those of the upper extremities. In the case of $\mathrm{T}$. D- the symptoms were similar, but the coma was not so profound; in his case vomiting had occurred earlier, and this was made more complete by the early administration of mustard and water. In both cases the injected and suffused conjunctivæe and the contracted pupils made a very striking picture. The bailiff aied in about six hours after taking the poison, and the lad in about eight hours. The fact that both patients were profoundly under the influence of the poison when first seen, that their mouths and gullets were severely burnt by the acid and the knowledge that both had vomited freely, and

15 Le Paris Médical, May, 1877, quoted from MacNeill. 16 Amer. Journ. Med. Sciences, 1876! milk and oils had been administered, tended to show that the use of the stomach-pump after the lapse of nearly three hours would be productive of more harm than good, so the treatment adopted was the application of warmth, the giving of oil and milk, and a solution of sulphate of soda as an antidote. The boy also had adrachm of etheradministered, but its effect was only slight.

A post-mortem examination of the body of T. D-was performed on Jan. 2nd, forty hours after death, and the features that obtained in his case would apply more or less to the other. There was much post.mortem staining of dependent portions of the body; the rigor mortis was passing off. There were yellowish stains around the mouth, and much frothy mucus about the lips and flowing from the nose. The membranes and vessels of the brain were much congested; the lateral ventricles contained about three drachms of fluid each, which had a faint odour of carbolic acid. The choroid plexus was of a deep purple colour. The mucous membrane of the mouth, pharynx, and cesophagus was corroded by the acid, and peeled off readily. The mucous surface of the stomach was of a deep-red colour, sodden, and detached in places, and coated with tenacious mucus, with hæmorrhagic spots scattered here and there; it contained a little oil and milk and emitted a strong odour of carbolicacid. Thesmall intestine was distended with gas and congested. The liver, kidneys, and especially the spleen, were congested. The bladder contained half an ounce of urine, which was of a greenish colour and had the odour of carbolic acid. The pericardium contained half an ounce of fluid which smelt faintly of carbolic acid. The heart's action had been arrested in diastole, the left side being firmly con. tracted, and the right full of blood which had not coagulated. The larynx was unaffected, the lungs were emphysematous in parts, and the bases deeply congested. The right lung was almost universally adherent to the chest wall.

It seems a pity that the public generally are not better informed as to the fatal properties of carbolic acid, since it is in such general use at present. The remark was made at the inquest that the reason medical aid was not called in souner was because the patient's friends were not aware that carbolic acid was poisonous, and nowonder, for the liquid was kept in an ordinary spirit jar without any label indicating its poisonous nature. The schedule to the Pharmacy Act still excludes this potent and deadly poison from its official list in spite of remonstrances, and until this state of things is remedied we can only expect to meet with more and more fatalities of a kindred nature to this.

Port Talbot, Glamorgan.

\section{Clinital allotes:}

\section{MEDICAL, SURGICAL, OBSTETRICAL, AND} THERAPEUTICAL.

\section{A FRENCH CATHETER IN THE MALE BLADDER REMOVED BY SUPRA.PUBIC LITHOTOMY.}

By James E. Trevor, M.R.C.S., L.S.A.

THE history of the following case may prove of interest. showing the possibility and danger of a catheter, when carelessly used, escaping from the urethra in to the bladder.

A. R-, aged sixty-five, was admitted into the Ashburton County Hospital, New Zealand, on Oct. 15th, 1889. He had had difficulty in passing his urine for the last eleven years, often finding the use of a catheter necessary. He said that he had never suffered from gonorrhoea or syphilis. In June last, directly after an attack of influerza, he experienced great pain in the region of the bladder, with inereased difficulty in voiding his urine, symptoms which continued till his admission into the hospital, with the addition that in the latter part of July he began to pass gravel, and continued to do so almost daily. The urine, which was discharged in a small stream, or by the aid of a catheter, was alkaline, contained a large quantity of pus and mucus, sometimes blood, and on standing became highly offensive. There was a stricture in the membranous portion of the urethra, which prevented the passage of the catheter beyond a No 3 soft or No. 5 